\title{
Optimization and Sizing of a Stand-Alone Photovoltaic System and Assessment of Random Load Fluctuation on Power Supply
}

\author{
Leonard Akana Nguimdo*, Clinton Kum \\ Faculty of Engineering and Technology (FET/EE), University of Buea, Buea, Cameroon \\ Email: *languimdo@yahoo.fr
}

How to cite this paper: Nguimdo, L.A. and Kum, C. (2020) Optimization and Sizing of a Stand-Alone Photovoltaic System and Assessment of Random Load Fluctuation on Power Supply. Energy and Power Engineering, 12, 28-43.

https://doi.org/110.4236/epe.2020.121003

Received: December 2, 2019

Accepted: January 12, 2020

Published: January 15, 2020

Copyright $\odot 2020$ by author(s) and Scientific Research Publishing Inc. This work is licensed under the Creative Commons Attribution International License (CC BY 4.0).

http://creativecommons.org/licenses/by/4.0/

(c) (i) Open Access

\begin{abstract}
This study presents an optimization technique and design for a stand-alone photovoltaic (PV) system to provide the required electricity for a single residential household in remote areas. From the basic solar components analysis, the irradiance on tilted surface is derived and compared to that on horizontal surface for Furu-Awa locality to infer the appropriate tilt angle $(\beta)$ that maximizes the collection of solar energy. Seven optimum values of $\beta$ applicable to the PV network were then derived depending of the period of the year and this simulation resulted that the panels are to be adjusted seven times a year. The optimization technique for load demand based on total apparent power of the household appliances produces an increase of $18 \%$ compared to the simple case of the PV components design using active power but leads to the optimum configuration that meets the real load demand of the household. Following the sizing of the station, reliability tests simulations were conducted for a one year corresponding period to infer the sensitivity of power supply to initial state of charge, to check the system autonomy and to evaluate the effect of random variation of the load on the smooth functioning of the PV system using a pseudo random number generator. This analysis shows that the minimum capacity of the battery for normal run of the Plan is $22.2 \%$ and that with random fluctuation of load, there will be periods of the year where the system experiences power failure depending on how important is the variation. The result of the study may imply a small increase in the cost of the entire plant but improves the stability and flexibility of such a station.
\end{abstract}

\section{Keywords}

Photovoltaic System, Optimization, Apparent Power, Tilt Angle, State of Charge, Random Numbers Generator 


\section{Introduction}

Photovoltaic (PV) system has received great attention as it appears to be one of the most promising renewable energy sources. The absence of an electrical network in some parts of the world, especially in remote areas has caused people to explore alternative solutions such as stand-alone power systems. The performance of a stand-alone PV system depends on the solar radiation, size of PV array, and storage capacity [1]. Therefore, the correct sizing plays an important role on the reliability of the stand-alone PV systems. Sizing methods are classified as intuitive, numerical and analytical methods. The first group algorithms are very inaccurate and unreliable because it deals with instinctive knowing (without the use of rational processes) and the probability of having final result wrong is very high. The second is more accurate, but algorithms need long time series of solar radiation for appropriate simulation [2]. In the third group, there are methods that use equations to describe the PV system size as a function of reliability which is what this research is all about, that is, maximizing the PV module output power and minimizing the life cycle cost of the system. This method gives the clear description of the solar geometry and analyzes the solar irradiance from the source to the surface of the tilted panels making the final result more reliable [3]. Most of the energy coming from the sun arrives in straight line and a solar panel or solar array will capture more energy if it is facing directly at the sun, perpendicular to the straight line between the position of the panels installation and the sun [1]. We then need to have the solar panel turned towards the terrestrial equator (either facing south in the northern hemisphere, or north in the southern hemisphere) so that during the day its orientation allows the panel to catch the greatest possible amount of solar radiation.

The demand for electricity to meet the need of the society is increasing at an alarming rate in most countries of the world, especially in Cameroon. To meet these needs, Cameroon and some neighboring countries such as Nigeria (with high usage of generators) are now seeking alternative sources of energy besides the rapidly depleting and polluting fossil fuels that the current infrastructure has become dependent upon [4] [5] [6]. The use of solar energy Photovoltaic (PV) technology presents one of the most promising renewable alternative energy sources for developing economies especially now that this technology for energy production to meet residential needs has been promoted for years now by some renewable energy companies and environmental organizations [7]. However, due to low conversion efficiency exhibited by photovoltaic systems, there has been great research interest in the optimization of maximum power and energy production under different climatic conditions. The amount of solar energy incident on a solar panel at any time is a complex function of many factors including the local radiation, latitude, longitude, location of the earth with respect to the sun, the orientation and tilt of the exposed solar panel surface, ground reflection properties, etc. [7] [8]. Besides the amount of solar irradiance reaching the surface of the panels, it is much vital to know how to extract the maximum of that energy to supply a residential area or the grid at the lowest possible cost 
and better reliability [9]. That is, having a very good output at a lower cost. In order to solve the problem of inaccurate assumptions in PV systems parameters and poor power evaluation of load which usually leads to high cost of purchase of materials and installation, Tamer Khatib et al. [10] provided highlights on challenges and limitations of standalone PV system size optimization techniques. Tao Ma et al. [11] in the same track proposed a novel sizing model to optimize the capacity of PV generator for power supply in remote areas using pumped storage. Their results show that zero power failure hours could be reached with a low cost of energy (COE) but the system does not harness the maximum solar power available locally. Al Riza et al. [12] introduced in their PV systems analysis the notion of daily battery condition for better reliability using minimum loss of power supply probability, minimum excess energy and minimum cost constraints. However, further control should be laid on the respect of the load profile and its random variation since it is a probabilistic and time varying parameter.

Besides the optimum load evaluation and adequate power generation and consumption, the present study introduces the idea of autonomy test and system sensitivity, where the sensitivity of power supply to initial state of charge and random load variation was studied to check the flexibility and reliability of the system. We investigate here optimum tilt angles that can be mechanically applicable to the panel network relative to the period of the year so as to maximize the energy collection at low cost. We focus on characterizing the effective load used in PV system installation so as to better size and optimize the system and for more reliability. The effect of random fluctuation of load demand on the state of charge is also studied in this work.

\section{Methodology}

\subsection{Solar Data Collection}

Data of the irradiance on horizontal surface that we use in this work are obtained from Photovoltaic Geographical Information System (PVGIS) [13] since there is no reliable ground-based measured data set for Furu-Awa $\left(6.87^{\circ} \mathrm{N}\right.$, $10.03^{\circ} \mathrm{E}$ ) locality. PVGIS is an official website of the European Union that provides a free and open web access to solar radiation and temperature data and to PV performance assessment tools. It contains different solar radiation databases (based on satellite data and reanalysis products) and covers Europe, Africa, Asia and part of America. The site provides long time daily values of irradiance taking a one hour step from January to December from which hourly averages were derived for monthly time scale, leading to twelve values for each month. These averages are then considered as daily values of irradiance for the different mean solar days for each month of the year for Furu-Awa following Akana and Njomo [14].

\subsection{Household Load Configuration and Load Demand}

The household chosen in Furu-awa was an average house with common ap- 
pliances such as TV, bulbs, electric iron, standing fan, fridge, etc. Table 1 presents the electrical load demand of the household in VA taking strictly into consideration the fact that not all the loads are DC and also that AC loads consume reactive power. The load profile derived from long term monitoring of energy consumption of the household and assumed to be constant throughout the year is as shown in Figure 1.

\subsection{Tilt Angle Optimization Technique}

The incident radiation on a tilted surface that takes into consideration the direct, diffuse and reflected solar irradiances [3] [7] [8] can be expressed as a function of the global irradiance $I$ on horizontal surface by

$$
\frac{I_{T}}{I}=\left(1-\frac{I_{d}}{I}\right) \frac{\cos \theta}{\cos \theta_{z}}+\frac{I_{d}}{I} \frac{1+\cos \beta}{2}+\rho \frac{1-\cos \beta}{2}
$$

Table 1. Electrical load demand of the household.

\begin{tabular}{ccccccccc}
\hline $\begin{array}{c}\text { Electrical } \\
\text { Load }\end{array}$ & $\begin{array}{c}\mathbf{N}^{\bullet} \text { of } \\
\text { Units }\end{array}$ & $\begin{array}{c}\text { Operating } \\
\text { hours } \\
\text { per day }\end{array}$ & $\begin{array}{c}\text { Active } \\
\text { Power }\end{array}$ & $\begin{array}{c}\text { Power } \\
\text { Factor }\end{array}$ & Mode & $\begin{array}{c}\text { Reactive } \\
\text { Power }\end{array}$ & $\begin{array}{c}\text { Apparent } \\
\text { Power }\end{array}$ & $\begin{array}{c}\text { Energy } \\
\text { Per Day }\end{array}$ \\
\hline TV & 1 & 8 & 250 & 0.95 & AC & 83 & 264 & 2112 \\
Lights & 5 & 12 & 15 & 1 & AC & 0 & 15 & 180 \\
Refrigerator & 1 & 12 & 200 & 0.7 & AC & 205 & 287 & 3444 \\
Laptop & 1 & 4 & 64 & 1 & DC & 0 & 64 & 256 \\
Electric iron & 1 & 0.5 & 1000 & 1 & AC & 0 & 1000 & 500 \\
Mobile phone & 4 & 8 & 8 & 1 & DC & 0 & 8 & 64 \\
TV Decoder & 1 & 8 & 35 & 0.9 & AC & 17 & 39 & 312 \\
Moulinex & 1 & 0.05 & 600 & 0.7 & AC & 613 & 858 & 43 \\
Security system & 1 & 10 & 2 & 1 & DC & 0 & 2 & 20 \\
Standing Fan & 1 & 8 & 100 & 0.75 & AC & 89 & 134 & 1072 \\
& & & Total & 8003 VAh/Day & & &
\end{tabular}

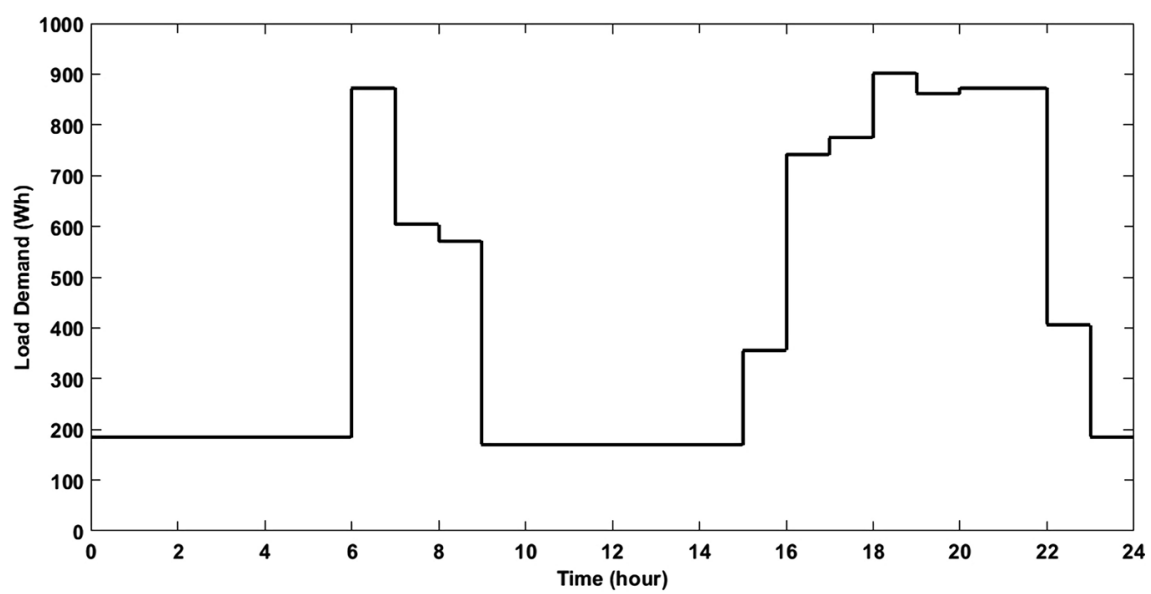

Figure 1. Load profile of the household. 
where

$I_{T}$ is the incident irradiance on the tilted surface and $I_{d}$ the diffuse irradiance on the horizontal surface. $\beta$ and $\rho$ are tilt angle and surface reflectivity respectively. $\theta_{z}$ and $\theta$ are solar zenithal angle and incident angle on the tilted surface respectively. The ratio $\frac{I_{d}}{I}$ is a function of the clearness index $(K)$ of the site and is defined as follows [15].

$$
\frac{I_{d}}{I}= \begin{cases}1-0.09 K & \text { for } K \leq 0.22 \\ 0.9511-0.1604 K+4.388 K^{2}-16.638 K^{3}+12.336 K^{4} & \text { for } 0.22<K<0.8 \\ 0.165 & \text { for } K \geq 0.8\end{cases}
$$

Following Khaled and Doraid [16] who considered a single tilt angle of the panels to be equal to the latitude of their site, we analyzed the case of Furu-awa to come out with the comparison of the total daily solar radiation on the horizontal and that on a $6.87^{\circ}$ (latitude of the site in this study) tilted surface as shown in Figure 2. In doing this, the values for the mean solar days for each month as outlined in Table 2 were used.

It was noticed that similar to Khaled and Doraid there are periods in the year where the total solar energy incident on the inclined surface is less than that on the horizontal. This proves once more the fact that considering a unique tilt is not optimal.

Our optimization technique is therefore aimed at deriving efficient tilt angles at particular periods of the year considering the fact that a fixed tilt angle is not optimal due to some climatic and environmental factors which vary throughout the year such as seasonal changes. This method improves the collection efficiency without inducing additional cost compare to tracking systems. The calculations were done considering the values of the solar geometry parameters for each particular mean solar day and assuming the result to be the average value for the month. In this operation the irradiance on the tilt surface $I_{T}$ is evaluated with tilt angles varying in the range $0 \leq \beta \leq 90$ (where $\beta$ is the tilt angle) [15] [16] [17] [18] [19]. Using the values of the ratio $\frac{I_{T}}{I}$ obtained at hourly time scale and

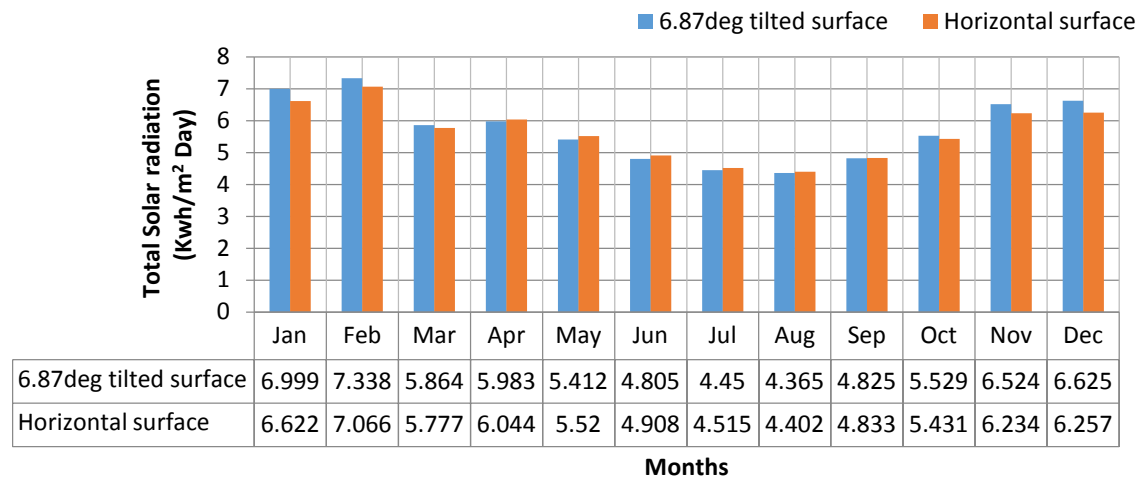

Figure 2. Monthly average daily solar radiation on horizontal surface and on a $6.87^{\circ}$ tilted plane at Furu-Awa. 
Table 2. Mean solar days at Furu-Awa [14].

\begin{tabular}{cccccc}
\hline \multirow{2}{*}{ Month } & Klein days & \multicolumn{3}{c}{ Computed mean solar day } & $\begin{array}{c}\text { Daily duration } \\
\text { (Hours) }\end{array}$ \\
\cline { 2 - 5 } & Number of the day & Date & Number of the day & Date & 17 \\
January & 17 & 17 & 17 & 14 & 11.99 \\
February & 47 & 16 & 45 & 1 & 12.01 \\
March & 75 & 16 & 60 & 16 & 12 \\
April & 105 & 15 & 106 & 15 & 12 \\
May & 135 & 15 & 135 & 12 & 12.03 \\
June & 162 & 11 & 166 & 17 & 11.99 \\
July & 199 & 17 & 198 & 16 & 12.01 \\
August & 228 & 16 & 228 & 13 & 12 \\
September & 258 & 15 & 256 & 18 & 11.88 \\
October & 288 & 15 & 291 & 15 & 12 \\
November & 318 & 14 & 319 & 9 & 11.99 \\
\hline December & 344 & 10 & 343 & & \\
\hline
\end{tabular}

throughout the month, profiles of total daily energy incident on the tilted surface for each month were then derived with the optimal $\beta$ corresponding to the highest energy received.

\subsection{Designing the PV Network}

This section presents the sizing of the PV system components. The design is based on the solar radiation of the average lowest month and the energy demand consisting of AC load and DC load separately. The storage capacity of the battery following Esan Ayodele and Egbune [20] and modified to suit the configuration of Figure 3 can be calculated according to

$$
\text { Storage capacity }=\frac{N_{c}}{D O D \times \eta_{q} \times \eta_{B}}\left[\frac{E_{A C}}{\eta_{i}}+\frac{E_{D C}}{\eta_{c}}\right]
$$

where $\eta_{i}, \eta_{q}, \eta_{c}$ and $\eta_{B}$ are the efficiencies of the inverter, charge controller, DC/DC converter and battery respectively. $N_{c}$ is number of autonomous days (i.e. the largest number of continuous cloudy days of the site considered in this study to be 3 days (following in situ evaluations). $D O D$ is maximum permissible depth of discharge of the battery. $E_{A C}$ and $E_{D C}$ are the total AC and DC electric loads demand respectively.

\subsubsection{Design of the Charge Controller}

The primary function of a charge controller in a stand-alone PV system is to maintain the battery at the highest possible state of charge while protecting it from over-charge by the array and from over discharge by the loads. A charge controller should prevent overcharge of a battery regardless of the system sizing/design and seasonal changes in the load profile, operating temperatures and 


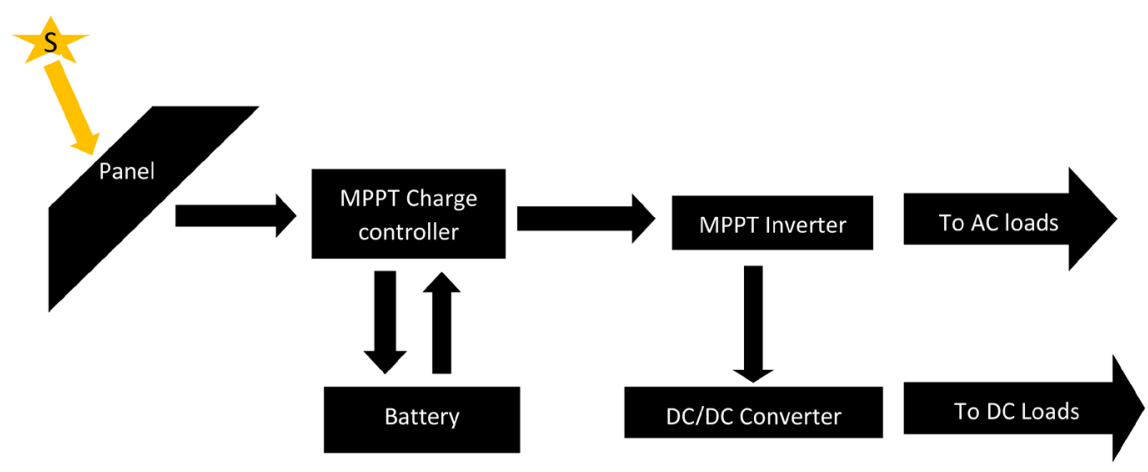

Figure 3. Schematic of household PV system design.

solar irradiation. It has to be capable of carrying the short circuit current of the PV array and maintain the DC bus voltage. The solar charge controllers that best fit those specifications are MPPT types that we chose in this study.

\subsubsection{Sizing of the Inverter, Battery and DC/DC Converter}

An appropriate inverter must be able to handle the maximum expected power of AC loads. The rated power of the inverter $P_{\text {rated }}$ in this study is $20 \%$ higher than the combined peak power of the total AC load needed at a particular time in a day from the load profile. This is to take care of the losses in the inverter itself and on the line (i.e. cables). The input DC voltage must be equal to the output of the charge controller. The MPPT inverter was chosen in this study with an efficiency $\eta_{i}$ of 0.94 .

Due to a well-established manufacturing base and its low cost, lead acid batteries have been extensively used in PV power plants. The efficiency of the lead acid battery $\eta_{B}$ from the datasheet is 0.84 and the maximum depth of discharge is 0.8 , that is, a fully charged battery can only discharge $80 \%$ of its storage capacity while withholding $20 \%$ for security purposes. This is done by the help of the charge controller. The sizing method for battery storage is based on the concept of power supply during a number of autonomous days where the load demand is met solely by the storage system. If the largest number of continuous cloudy days (number of autonomous days) is $N_{\odot}$ then the minimum required ampere hours of the battery $A h_{\text {totB }}$ is calculated by

$$
A h_{\text {totB }}=\frac{\text { Storage capacity }}{\text { DC nominal voltage }}
$$

Depending on the characteristics of a battery, the number of batteries in parallel $N B_{p}$ is calculated as follows;

$$
N B_{p}=\frac{A h_{\text {totB }}}{\text { rated capacity in Ampere hours }}
$$

Finally, the total number of batteries needed can be calculated as follows

$$
\text { Total batteries needed }=N B_{P} \times N B_{S}
$$

where $N B_{S}$ is the number of batteries in series which can be computed depending on the DC voltage $V_{s}$ needed at the level of the inverter's input and the DC 
voltage $U$ of each battery according to $N B_{S}=\frac{V_{S}}{U}$.

The DC/DC converter is used to supply the DC loads of the household such as the phones and Laptop. It is designed in such a way that it outputs 19 and 5 volts with efficiency $\eta_{c}$ of 0.95 .

\subsubsection{Sizing of PV Modules}

The total watt-peak rating $\left(P_{\text {peak }}\right)$ needed for the PV modules to operate the home appliances is a function of the total watt-hours per day needed from the $\mathrm{PV}$ module and the panel generating factor $(P G F)$ and is defined as

$$
P_{\text {peak }}=\frac{\text { Total Energy Needed per Day }}{\text { Panel Generation Factor }}
$$

The panel generating factor that varies for different locations is obtained by taking into consideration the correction factor (Performance Ratio) for a solar PV module that takes care of losses due to environmental and climatic conditions and is equal 0.69 when MPPT charge controller is used or 0.62 if not [20] [21]. PGF is therefore defined by

$$
P G F=I_{T}\left(\mathrm{KWh} / \mathrm{m}^{2} / \text { Day }\right) \times \text { Total correction factor on the solar panels }
$$

The total number of PV panels needed is obtained by dividing the total Watt-peak of PV farm by the rated the capacity of a single solar panel.

$$
N_{T}=\frac{P_{\text {peak }}}{\text { rated output peak of the PV available }}
$$

The number of modules in series $N M_{s}$ and parallel $N M_{p}$ are calculated as follows:

$$
N M_{s}=\frac{V_{s}}{V_{M}} \text { and } N M_{p}=\frac{N_{T}}{N M_{s}}
$$

where $V_{s}$ is system nominal voltage and $V_{M}$ the module rated voltage.

The system nominal voltage topology was 48 volts and the selected modules for this study are PS-M72 mono-crystalline silicon, with the following specifications at standard test conditions (i.e., $1000 \mathrm{~W} / \mathrm{m}^{2}$ and $25^{\circ} \mathrm{C}$ ): Peak power of the module equals $300 \mathrm{~W}$, Nominal Output Voltage 24 Volts.

\subsection{PV System Configuration}

The basic configuration of a PV stand-alone system shown in Figure 3 is considered in this study. The system consists mainly of solar panels, MPPT charge controller and inverter, batteries, DC/DC converter and load. The DC/DC converter is to supply mainly the DC loads while the inverter supplies only the AC loads.

\section{Result}

\subsection{Tilt Angle Analysis}

Figure 4 presents the profile of monthly averaged daily total solar radiation for 

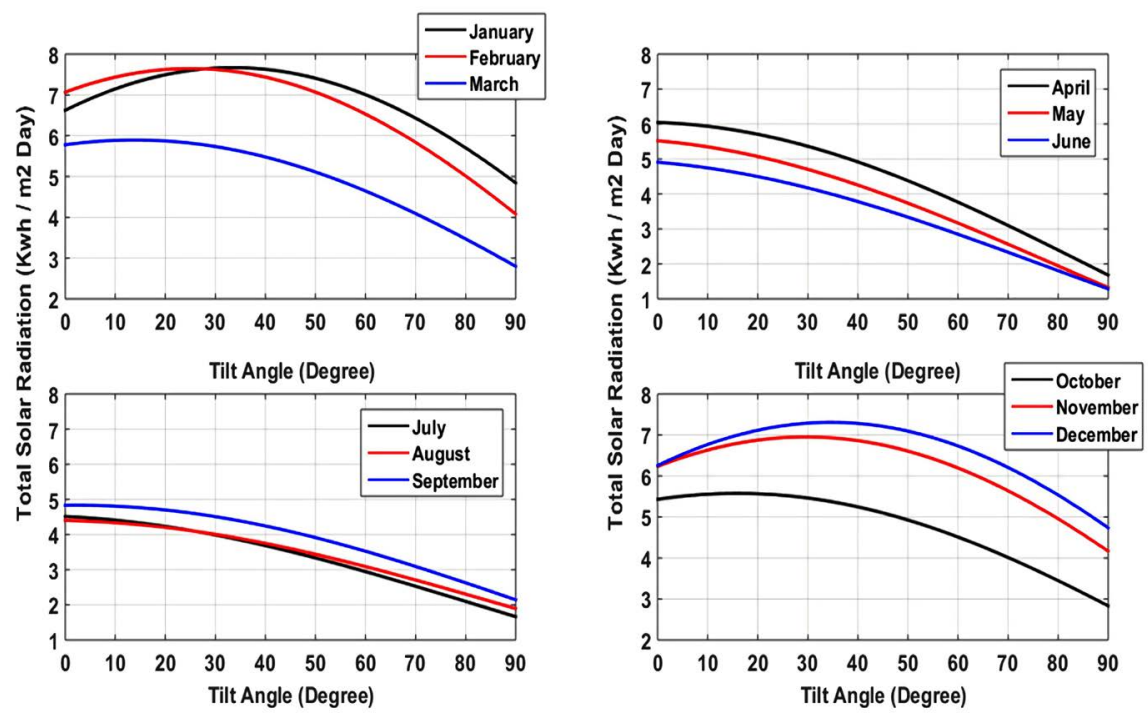

Figure 4. Variation of monthly averaged daily total solar radiation for various inclination angles at Furu-Awa.

various inclination angles at Furu-Awa. The objective here to make sure that the panels are placed in such a way that the incident energy on a tilted panel is maximum throughout the year is achieved. It is apparent that the lowest value of daily total solar radiation is found for $90^{\circ}$ inclination angle for all the months. In fact, sun rays tend to be parallel to the receiver surface for such an inclination. The highest in turn is found at different inclination angles including $0^{\circ}$ tilt. It can be clearly seen from the graphs that the maximum is not obtained for $\beta=$ $6.87^{\circ}$ (latitude of Furu-Awa) though this tilt gave higher values compared to horizontal for some months (see Figure 2). The optimum tilt angle increases from September and reaches its maximum value of $35^{\circ}$ in December from where it decreases to $14^{\circ}$ in March. For the period ranging from April to August, the common optimum $\beta$ is zero degree. However, the total daily radiation during this period is higher than that for a single tilt equal to latitude.

These results indicate that contrary to most approaches that mostly consider a single optimal tilt angle throughout the year, the panels are adjusted many times in a year to be able to harness the maximum of the solar energy. It is important to indicate that the change in the tilt does not induce additional cost compare to tracking systems since it is done manually and maximum once per month using a simple mechanically system that is attached to the PV array frame and does not need additional personnel.

Using the optimum tilt angles, Figure 5 compares monthly averages of solar radiation on horizontal plane, $6.87^{\circ}$ tilt and that of optimal tilt angles for each month of the year at Furu-Awa.

This result contrasts the one in Figure 3 where for 6 months the horizontal solar radiation is greater than that of the tilt. By varying the tilt angle, the months where the horizontal irradiance was greater than the tilt irradiance for fixed tilt have been clearly compensated. Also the months where $I_{T}$ was already 


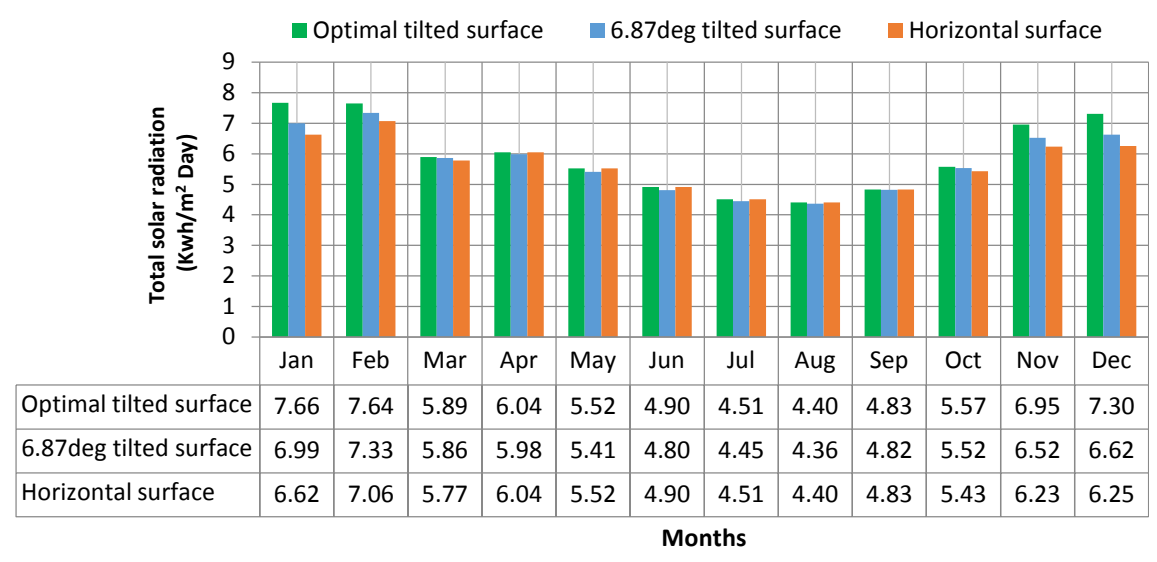

Figure 5. Monthly average daily irradiance on a horizontal surface and on a variable tilted plane for different months at Furu-Awa.

greater than the horizontal, that is, from October to March for fixed tilt (see Figure 3) have been greatly improved with the highest increase of $16.79 \%$ obtained in December. This approach is particularly interesting since it does not have an impact on the global cost of the plant being in terms of material acquisition or maintenance. It simply needs a rotatory system that allows varying mechanically the angle depending on the period. This optimization technique which can be applied anywhere in the world for stand-alone PV systems yields better reliability. However, the fact that zero tilt ie horizontal surface is optimal could bring in mind that during these periods the panels can be placed horizontally, but this is not advisable due to the fact that the panels being horizontal will collect and keep a lot of particles like dust and birds droplets and also keep standing water, and this will intend to affect the operation of the system by reducing the output power.

\subsection{PV System Design}

The following results were obtained from the design criteria for the different components of the PV system discussed in the previous section. The lowest average solar radiation $I_{T}$ obtained from Figure 5 is $4.402 \mathrm{KWh} / \mathrm{m}^{2} /$ Day (August). The storage capacity from Equation (2) considering 3 days of autonomy gives $38.375 \mathrm{kWh}$. For lead acid battery with nominal voltage of 12 volts and rated capacity equals $220 \mathrm{Ah}$, then the minimum required Ampere hours of the battery $A h_{\text {totB }}$ from Equation (4) with a DC nominal voltage of 48 volts gives 800 $\mathrm{Ah}$, hence the total number of batteries in parallel from Equation (4) is 4 batteries. This implies that the total number of batteries needed for the system from Equation (5) is 16 batteries.

The rated power of the inverter from Figure 1 applying a correction factor of 1.2 to the peak load demand (that is, from 5 to $6 \mathrm{pm}$ having the maximum load demand in VA) is 1900 VA with a DC voltage of $48 \mathrm{~V}$ and $50 \mathrm{~Hz}$ frequency.

As far as the PV modules are concerned, the performance factor is 0.69 since MPPT controller is considered. The Panel Generation Factor considering the 
lowest solar irradiation then gives 3.037. The actual load demand is given by:

$$
E_{\text {actual }}=\frac{10^{-3}}{\eta_{q} \times \eta_{B}}\left[\frac{E_{A C}}{\eta_{i}}+\frac{E_{D C}}{\eta_{c}}\right]=\frac{1}{0.99 \times 0.84}\left[\frac{7663}{0.94}+\frac{340}{0.95}\right]=10.238 \mathrm{KWh} / \text { Day }
$$

The total peak power of the plant equals $3371.1 W_{p}$ and the total number of panels for the PV system 12. The number of modules needed in series and parallel was found to be 2 and 6 respectively.

\subsection{Autonomy Test and System Sensitivity}

\subsubsection{Sensitivity of Power Supply to Initial State of Charge and Random Load}

In conventional PV plants, power fluctuations are counter balanced by the use of battery storage systems which ultimately is a key element of the plant since a small increase in its size results in a large increase in the overall cost of the plant. Although power fluctuations have the effect of reducing the life-time of the battery storage system, the state of charge is closely monitored in PV plant that can be stopped when the maximum depth of discharge is attained. Starting from $20 \%$ of maximum storage capacity ( $800 \mathrm{Ah}$ ) for our plant, we set the plant on and studied the state of charge for a corresponding period of one year as presented in Figure 6.

The graph shows that for a continuous supply of the household, a minimum of $22.2 \%$ of ampere hours should available in the battery under local irradiance conditions. From this value the maximum capacity $(800 \mathrm{Ah})$ for a smooth functioning of the plant is observed after 33 hours that is after and equivalent period of 41 days. When the initial capacity is $25 \%$ and $40 \%$ respectively, the system needs 32 hours and 31 Hours to achieve full batter charge. This period reduces to 3 hours when the system is set at full charge. This result indicates how important it is to respect the load demand since a small variation during the first 24

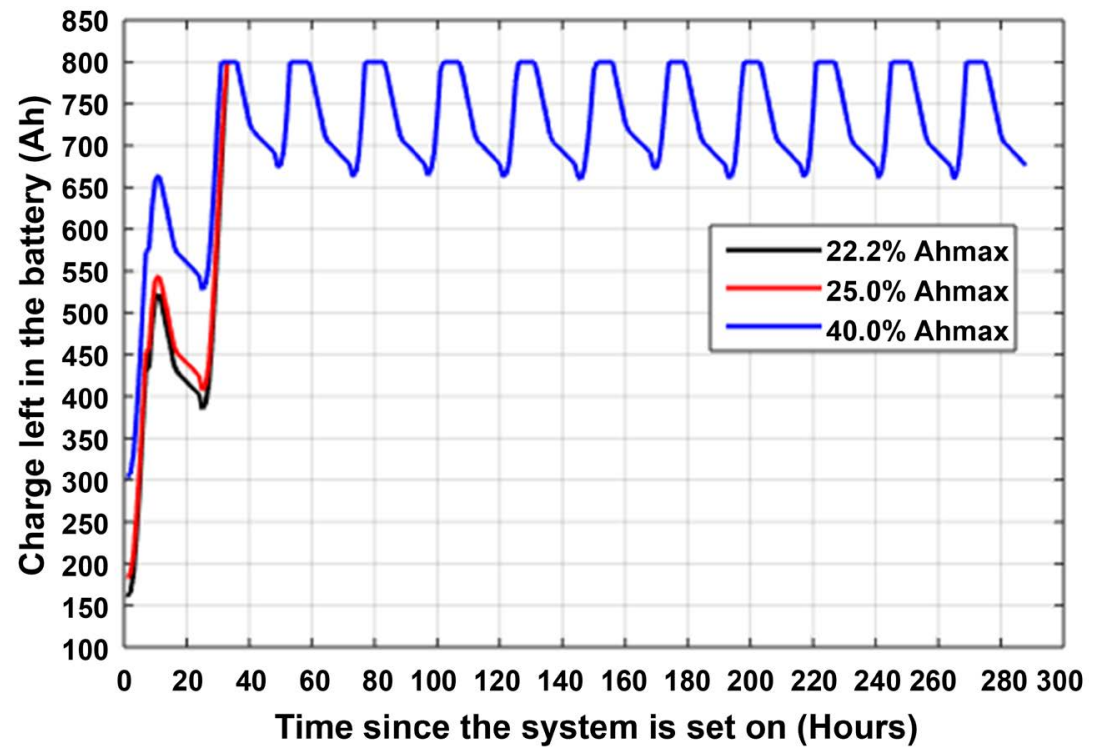

Figure 6. Sensitivity of power supply to initial state of the battery. 
hours following the start of the plan may cause a power failure. To emphasize on the impact of load fluctuation, we undertook a random variation of the load using a pseudo random number generator ran2 that delivers random numbers ranging from 0 to 1 with a periodicity of $\left(2^{63}-1\right)$. The load profile for a period of 72 Hours in shown on Figure 7. The black curve corresponds to normal load assumed to be constant for a given time interval every day. In turn random load at a specific time will not have the same value the next day at the same time depending on the random value at that precise moment. For illustration, the normal load of $185.5 \mathrm{KWh}$ at Time $=0,24,48$ hours (which refer respectively to the same instant for three consecutive days) becomes respectively 230.2, 238.2 and $258.7 \mathrm{KWh}$ when the load is modified by $0.4 \times$ ran 2 .

Figure 8 presents the state of charge of the battery for random fluctuation of load. The plant functions throughout the entire period in the case of minimum change $(0.1 \times$ ran 2$)$. However, it can be noted that the variation in the charge left in the battery becomes more and more important toward the end of this period. This may indicate that there is a potential risk of power failure if the energy consumption is not controlled. It is important to indicate that in this case, the maximum random increase in the load of $129 \mathrm{Wh}$ (at Time $=66$ hours, see Figure 7) corresponds to the refrigerator working for less than 30 minutes above the indicated time. For the $0.3 \times$ ran2 load modification, the plant does not function continuously in the year and stops after 183 hours. This time corresponds to the plant functioning for 7.62 months. This period reduces to 6 months for $0.4 \times$ ran2 load modification. These limitations in power supply prove how important it is to respect the load profile of the household.

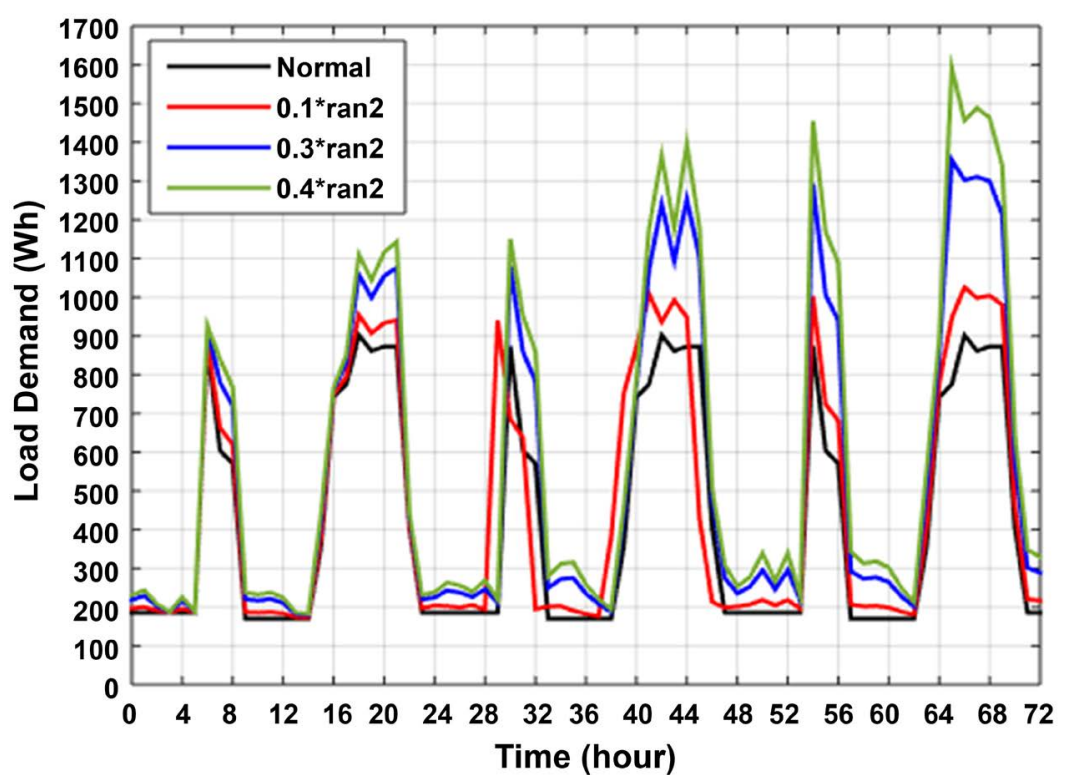

Figure 7. Random load generated using ran2. The black curve corresponds to normal load assumed to be constant throughout the day. To avoid cases where the load doubles which may not be realistic, coefficients $0.1,0.3$ and 0.4 are used to scale the variation. The modified load is therefore defined as Load $=$ Load $(1+0.1 \times \operatorname{ran} 2)$ in the case of coefficient $=0.1$. 


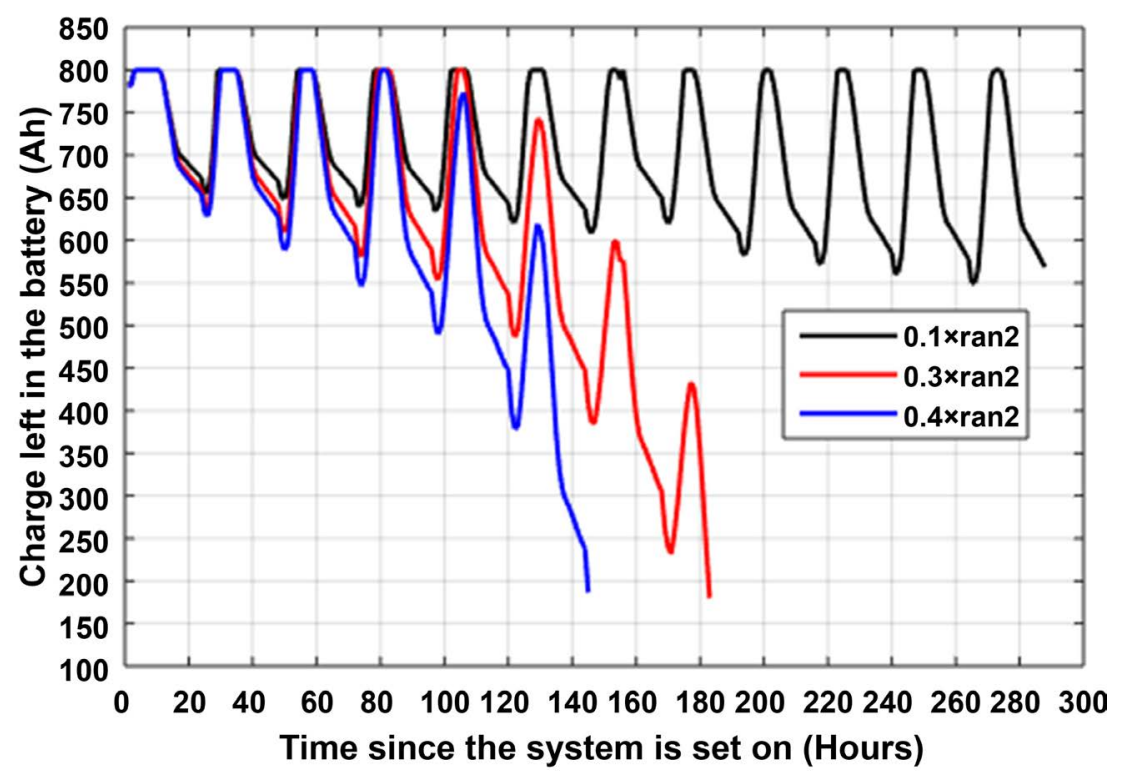

Figure 8. Impact of random fluctuation of load on the state of charge of the battery.

\subsubsection{Autonomy Test}

For autonomy test, the plant is launched when the battery is fully charged and the objective being to check whether the system can resist extreme cloudy conditions.

In the case of this analysis, three days autonomy where predicted. Following the curve in black (Figure 9), it is observed that the plan goes off exactly at Time $=72$ Hours that corresponds to the prediction. This result is of importance in an analytical and technical point of view since the design is based on lowest month solar radiation while the control test done here considers irradiance at hourly time scale. It is a fact that this condition is fulfilled only if the load profile is strictly respected since there is no power generation during this period. An alternative could be when panels receive a slight amount of irradiance. We considered $10 \%$ and $20 \%$ of the amount that is received under normal circumstances at hourly time scale. Figure 9 shows a little increase in autonomy where additional 22 and 49 Hours are observed for 10\% and 20\% irradiance respectively. However, it is important to mention that a slight increase in the load would significantly reduce this autonomy as can be seen in Figure 10. In fact, under no sunshine conditions, the autonomy reduces to 63 and 60 Hours for 0.1 $\times$ ran 2 and $0.2 \times$ ran 2 random change in load respectively.

\section{Conclusion}

This paper describes the optimum configuration of a stand-alone photovoltaic system and assesses the impact of random load fluctuation on power supply. This optimization was done using the concept of the best periodical inclination angle that allows maximum incidence on the panels and the use of effective power demand of the household. The estimation of solar radiation for tilted surfaces carried out by considering different solar geometry parameters and incident solar 


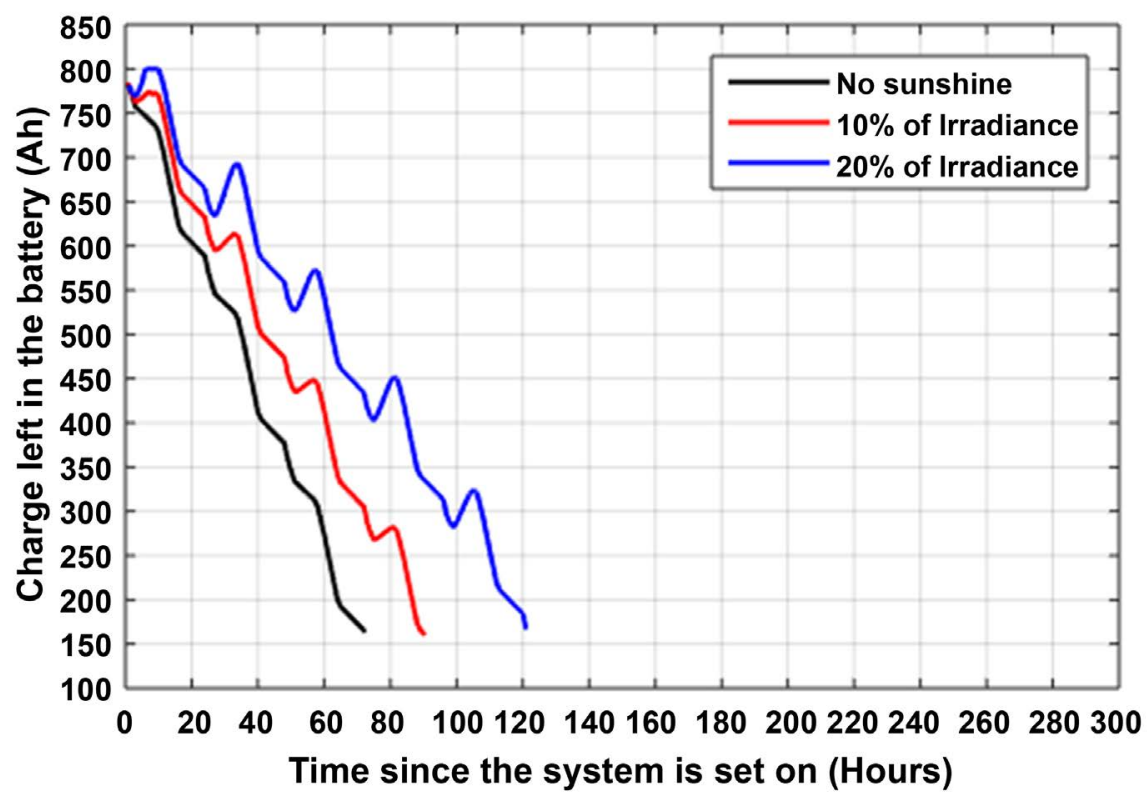

Figure 9. State of charge during periods of no sunshine and poor sunshine. Curves in red and blue refer to situations where at hourly time scale $10 \%$ and $20 \%$ of the irradiance are received.

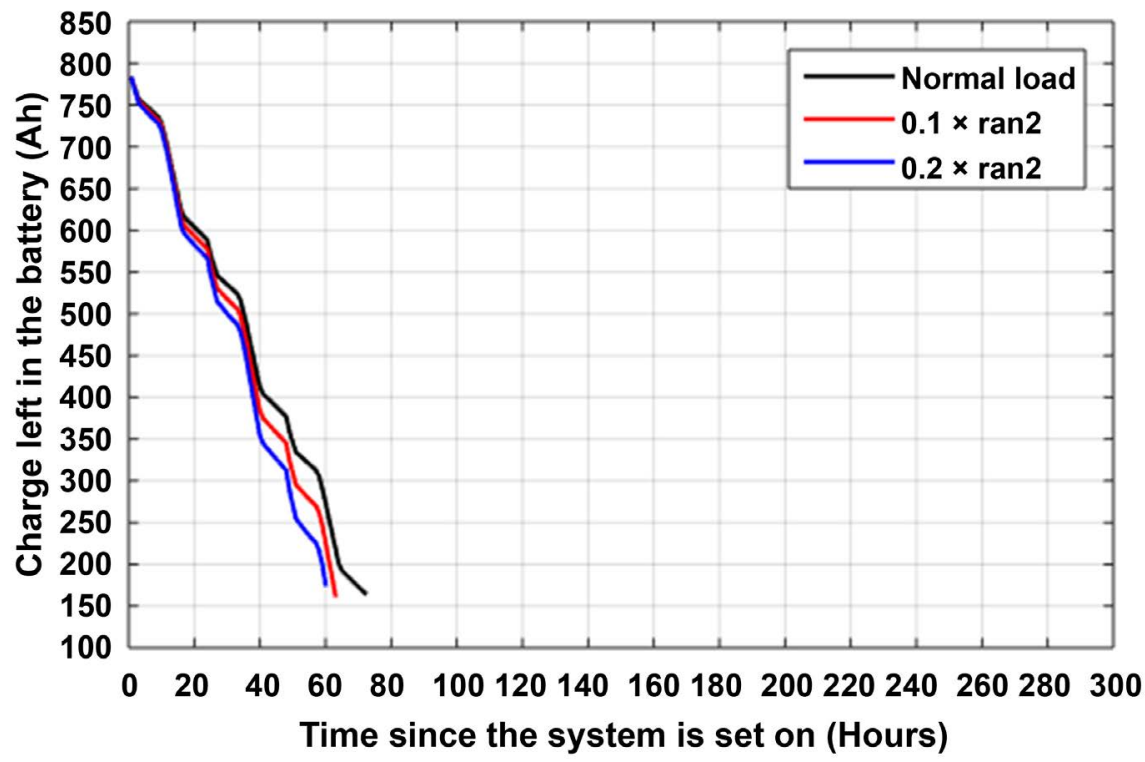

Figure 10. Impact of random load variation on the system autonomy. Curves in red and blue refer to $0.1 \times$ ran 2 and $0.2 \times$ ran2 load fluctuation respectively.

radiation at Furu-Awa indicates that the inclination angle must be varied 7 times yearly while the use of total apparent power overestimates the load demand at a rate of $18 \%$. However, these changes yield a better output at the level of panels and better reliability of the PV station. The analysis of random load variation shows that the load profile must be respected no matter the constraints. In fact, even the smallest increase in the load demand can be a potential source of power shortage in the plant. 


\section{Conflicts of Interest}

The authors declare no conflicts of interest regarding the publication of this paper.

\section{References}

[1] Kumar, A., Thakur, N.S., Makade, R. and Shivhare, M.K. (2011) Optimization of Tilt Angle for Photovoltaic Array. International Journal of Engineering Science and Technology, 3, 3153-3161.

[2] Elarini, M.M., Othman, A.M. and Mohamed, A.F. (2014) A New Technique Based on Artificial Bee Colony Algorithm for Optimal Sizing of Stand-alone Photovoltaic System. Journal of Advanced Research, 5, 397-408.

[3] Darhmaoui, H. and Lahjouji, D. (2013) Latitude Based Model for Tilt Angle Optimization for Solar Collectors in the Mediterranean Region. Energy Procedia, 42, 426-435. https://doi.org/10.1016/j.egypro.2013.11.043

[4] Muh, E., Amara, S. and Tabet, F. (2018) Sustainable Energy Policies in Cameroon: A Holistic Overview. Renewable and Sustainable Energy Review, 82, 3420-3429. https://doi.org/10.1016/j.rser.2017.10.049

[5] Ezennaya, O.S., Isaac, O.E., Okolie, U.O. and Ezeanyim, O.I.C. (2014) Analysis of Nigeria's National Electricity Demand. International Journal of Scientific \& Technology Research, 3, 333-340.

[6] Akter, M.S. and Shoeb, A. (2015) A Novel Model to Calculate Global Tilted Irradiation (GTI) from Solar Variables Using Netcdf and Rstudio. International Journal of Scientific \& Engineering Research, 6, 462-469.

[7] Islam, M.A., Alam, S., Sharker, K.K. and Nandi, S.K. (2016) Estimation of Solar Radiation on Horizontal and Tilted Surface over Bangladesh. Computational Water, Energy, and Environmental Engineering, 5, 54-69.

https://doi.org/10.4236/cweee.2016.52006

[8] Shukla, K.N., Rangnekar, S. and Sudhakar, K. (2015) Comparative Study of Isotropic and Anisotropic Sky Models to Estimate Solar Radiation Incident on Tilted Surface: A Case Study for Bhopal, India. Energy Reports, 1, 96-103. https://doi.org/10.1016/j.egyr.2015.03.003

[9] Ekanem, O.D. and Onojo, J.O. (2017) Determination of Yearly Fixed Optimal Tilt Angle for Flat-Plate Photovoltaic Modules Based on Perez Transposition Model. American Journal of Software Engineering and Applications, 6, 80-84. https://doi.org/10.11648/j.ajsea.20170603.14

[10] Khatib, T., Ibrahim, I.A. and Mohamed, A. (2016) A Review on Sizing Methodologies of Photovoltaic Array Storage Battery in a Standalone Photovoltaic System. Energy Conversion and Management, 120, 430-448. https://doi.org/10.1016/j.enconman.2016.05.011

[11] Ma, T., Yang, H., Lu, L. and Peng, J. (2014) An Optimization Sizing Model for Solar Photovoltaic Power Generation System with Pumped Storage. Energy Procedia, 61, 5-8. https://doi.org/10.1016/j.egypro.2014.11.892

[12] Al Riza, D.F., Gilani, H. and Aris, M.S. (2015) Standalone Photovoltaic Systems Sizing Optimization Using Design Space Approach: Case Study for Residential Lighting Load. Journal of Engineering Science and Technology, 10, 943-957.

[13] Hourly Solar Irradiance at Furu-Awa. http://re.jrc.ec.europa.eu/pvg tools/en/tools.html\#PVP 
[14] Akana, L.N. (2009) Spatial and Temporal Distribution of Downwelling Solar Radiation in Cameroon as Derived Using a Parameterized Solar Radiative Transfer Model in a Molecular Atmosphere. JP Journal of Heat and Mass Transfer, 3.

[15] Axaopoulos, P. Solar Radiation on Tilted Surface. https://www.labri.fr

[16] Bataineh, K. and Doraid, D. (2012) Optimal Configuration for Design of Stand-alone PV System. Smart Grid and Renewable Energy, 3, 139-147. https://doi.org/10.4236/sgre.2012.32020

[17] Maleki, S.A.M. and Hizam, H. (2017) Estimation of Hourly, Daily and Monthly Global Solar Radiation on Inclined Surface: Models Re-Visited. Energies, 10, 134. https://doi.org/10.3390/en10010134

[18] Axaopoulus, P. Basic Principles of Solar Geometry. https://www.labri.fr

[19] Julian Chen, C. (2011) Physics of Solar Energy. John Wiley \& Sons, Inc., Hoboken, NJ.

[20] Esan Ayodele, B. and Egbune, D. (2017) Estimating the Solar Home System Sizing for Rural Residential Apartments Using a Panel Tilt Angle of 82 Degrees: Ilorin, Kwara State as Case Study. Electrical and Computer Engineering, 1, 90-96.

[21] Tech, N.M. and Kunjithapathan, B. (2019) Design and Implementation PV Energy System for Electrification Rural Areas. International Journal of Engineering and Advanced Technology, 8, 2340-2352. 